\title{
DIPLOMASI EKONOMI INDONESIA \\ KE KAWASAN AFRIKA
}

\author{
Mariane Delanova \\ Universitas Jenderal Achmad Yani \\ Email: mariane.delanova@lecture.unjani.ac.id
}

\begin{abstract}
Abstrak
Negara Amerika, Jepang dan Tiongkok selama ini dikenal sebagai mitra dagang terbesar bagi Indonesia. Tidak mengherankan jika ekspor Indonesia banyak diarahkan kepada negara-negara tersebut. Akan tetapi, beberapa tahun ini nilai ekspor Indonesia terhadap negara-negara mitra dagang terbesar atau yang biasa disebut sebagai pasar non tradisional, semakin mengalami penurunan. Saat ini, berbagai upaya dilakukan oleh Pemerintah Indonesia. Salah satunya adalah dengan semakin mengintensifkan diplomasi ekonomi Indonesia kepada kawasan yang selama ini belum menjadi mitra dagang Indonesia. Kawasan-kawasan tersebut diidentifikasi menjadi pasar non tradisional Indonesia. Diplomasi ekonomi Indonesia semakin intens dan fokus diarahkan kepada kawasankawasan yang menjadi pasar non tradisional. Salah satunya adalah kawasan Afrika. Kawasan Afrika dianggap sebagai pasar non tradisional Indonesia yang memiliki potensi besar yang belum dieksplorasi oleh Indonesia. Penelitian ini bertujuan untuk menganalisis implementasi atau pelaksanaan diplomasi ekonomi Indonesia ke kawasan Afrika untuk mencapai kepentingan ekonomi Indonesia, utamanya adalah meningkatkan ekspor Indonesia yang pada akhirnya akan dapat meningkatkan kesejahteraan Indonesia.
\end{abstract}

Kata kunci : Diplomasi Ekonomi, Kawasan, Pasar Non Tradisional.

\section{PENDAHULUAN}

Diplomasi ekonomi Indonesia menjadi fokus dalam beberapa tahun terakhir kebijakan luar negeri. Indonesia. Hal tersebut sesuai dengan visi dan misi Presiden Joko Widodo (Jokowi) periode 2015-2019. Prioritas kebijakan luar negeri Indonesia salah satunya adala memperkuat kinerja diplomasi ekonomi Indonesia yang bertujuan untuk mendorong pertumbuhan perekonomian Indonesia dan meningkatkan kesejahteraan rakyat Indonesia. Apabila dilihat dari program Kementrian Luar Negeri Republik Indonesia 
(Kemlu RI), diplomasi ekonomi adalah fokus dalam kinerja Kemlu RI. Diplomasi ekonomi juga merupakan satu dari delapan arah kebijakan yang tercantum dalam Rencana Strategis (renstra) Kemlu RI tahun 2015-2019 (Sulthon Sjahril Sabaruddin).

Diplomasi ekonomi dianggap sebagai upaya dan kunci utama keberhasilan negara- negara berkembang untuk memanfaatkan potensi dan peluang ekonominya di negara lain. Tidak terkecuali Indonesia, pada masa kepemimpinan Presiden Jokowi fokus membangun diplomasi ekonomi yang diharapkan dapat diimplementasikan dalam kebijakan luarnegeri yang akan memberikan manfaat positif bagi Indonesia, seperti pembukaan pasar terhadap produk Indonesia.

Beberapa tahun terakhir, Indonesia mengalami penurunan nilai ekspor yang dimulai pada tahun 2011-2015. Nilai ekspor Indonesia mengalami tren penurunan sebesar $-6,59 \%$. Pada tahun 2011, nilai ekspor Indonesia sebesar US\$203 milyar, kemudian mengalami penurunan selama kurun waktu 5 tahun, sehingga pada tahun 2015 nilai ekspor yang dimiliki Indonesia sebesar US\$150.25 milyar (Ibid). Penurunan nilai ekspor Indonesia ditandai dengan penurunan ekspor non-migas ke negara mitra dagang besar Indonesia selama ini atau dikenal dengan pasar tradisional mulai tahun 20102014 dengan tren rata-rata penurunan sebesar 1,2\% per tahun. Penurunan terjadi juga disebabkan karena perlambatan ekonomi global yang mengakibatkan pertumbuhan ekonomi sejumlah negara tujuan ekspor Indonesia menurun (bppp.kemendag.go.id, diakses pada 25 Januari 2020).

Pada pertengahan tahun 2017, Presiden Joko Widodo dan Menteri Keuangan Sri Mulyani melakukan pertemuan dengan pelaku usaha dan ekonomi agar memberikan perhatian khusus dalam merespon potensi-potensi di luar pasar tradisional Indonesia selama ini. Pada kesempatan tersebut Presiden Jokowi menjelaskan beberapa kawasan seperti Afrika, Asia Selatan dan Amerika Latin yang adalah pasar non-tradisional, memiliki potensi yang dapat dikembangkan untuk memperluas pasar ekspor Indonesia. Salah satu kawasan disebutkan yang mendapat perhatian khusus adalah Afrika. 
Nilai ekspor non migas Indonesia ke Afrika Selatan dari tahun 20152018 terus meningkat, sejak tahun 2015 dengan nilai US\$ 896.267,5 pada akhir tahun 2018 mencapai angka US\$ 1.712.229,7 (www.kemendag.go.id, diakses pada 1 Februari 2020). Berdasarkan data Kementrian Perdagangan mengenai perdagangan Republik Indonesia (RI) dan Afrika, selama 2017 total perdagangan dan investasi Indonesia dengan Afrika sebesar US\$ 8,83 Miliar (Ekspor sebesar US\$ 4,86 miliar dan impor sebesar US\$ 3,97 miliar). Dan saat ini sudah ada lebih dari 28 perusahaan swasta dan juga BUMN telah melakukan kegiatan perdagangan, bisnis, dan investasi di Afrika (ksp.go.id, diakses pada 10 Februari 2020). Berdasarkan data-data di atas, dapat dikatakan bahwa potensi pasar di kawasan Afrika sangat besar.

\section{PEMBAHASAN}

\section{Neoliberalisme}

Neoliberalisme memiliki fokus kepada kerjasama atau kooperasi. Neoliberalisme ditandai dengan gagasan yang mengedepankan kepada deregulasi dan peraturan pasar, keterbukaan Badan Usaha Milik Negara (BUMN), campur tangan pemerintah yang terbatas, serta menginginkan pasar internasional yang lebih terbuka.

Dalam Neoliberalisme, ekonomi merupakan fokus bagi dan tujuan suatu negara. Meningkatkan perekonomian nasional merupakan hal yang fundamental, maka dalam neoliberalisme diyakini bahwa kestabilan dalam perekonomian akan menghindarkan suatu konflik di kemudian hari. Neoliberalisme juga lebih melihat kepada kebebasan aktor dalam melakukan kegiatan ekonomi dan kerjasama dengan aktor lain. Aktor yang berperan dalam Hubungan Internasional menurut neoliberalisme memiliki berbagai bentuk, dimulai dari individu, kelompok-kelompok seperti MNCs (Multinational Corporations), IGOs (International Government Organizations), INGOs (International Non-Government Organizations) atau yang dimaksud dengan Organisasi Pemerintah dan Non-Pemerintah. Neoliberalisme juga menganggap bahwa peran negara menjadi berkurang dan tidak mendominasi dalam 
Hubungan Internasional, karena peran Negara digantikan oleh pasar, sebutan bagi para aktor dalam Hubungan Internasional yang memiliki kepentingan ekonomi di dalamnya( Steans, J. and Pettiford L, 2005).

Selain itu dalam neoliberalisme sangat mempercayai kepentingan institusi yang di antaranya Organisasi Internasional (OI) atau Rezim Internasional sangat berpengaruh pada hubungan internasional. Mereka meyakini bahwa dengan adanya ketergantungan yang tinggi, negara-negara akan semakin sering dalam membentuk institusi-institusi internasional dalam upayanya menghadapi masalah-masalah bersama. Kaum neoliberal berpendapat bahwa institusi internasional seperti Perserikatan Bangsa-Bangsa (PBB), rezim internasional seperti rezim perdagangan melalui WTO (World Trade Organization) akan membantu dan memajukan kerjasama internasional dan menjadikan fasilitator sebagai institusi yang mewadahi dalam hubungan antar negara yang dibentuk (Budi Winarno, 2007: 119).

Menurut sejarahnya, dalam pendirian Neoliberalisme pada prinsipnya tidak bergeser dari teori liberalisme yang telah diutarakan oleh Adam Smith dalam bukunya The Wealth of Nations (1776). Diakibatkan dari krisis yang berkepanjangan yang menimpa kapitalisme pada abad ke-19 yang juga berdampak pada depresi ekonomi pada tahun 30-an. Dan akibatnya adalah runtuhnya liberalisme dan juga peran besar negara. Maka dinilai bahwa kapitalisme membutuhkan strategi yang baru dalam menciptakan percepatan pertumbuhan ekonomi. Strategi tersebut merupakan menghilangkan segala rintangan investasi dan perdagangan bebas, perlindungan pada hak milik intelektual, good governance, menghilangkan subsidi dan program proteksi pada rakyat, deregulasi, dan penguatan civil society dan anti korupsi. Maka cara yang diperlukan adalah membentuk suatu tatanan perdagangan yang baru dan memunculkan globalisasi. Dengan demikian, globalisasi berpijak pada kebangkitan kembali liberalisme dan juga yang biasa disebut dengan neoliberalisme (Mansour Fakih, 2004: 3). 


\section{Diplomasi Ekonomi}

Diplomasi adalah sebuah tindakan secara praktis yang dilakukan oleh sebuah negara melalui perwakilannya yang dalam pelaksanaannya melibatkan negosiasi mengenai berbagai isu dalam hubungan internasional (Ronald Peter Barston, 2006: 1). Diplomasi dapat dikatakan sebagai salah satu media yang digunakan oleh negara untuk kemudian menunjukkan dan mengkomunikasikan pendirian dan pandangannya terhadap suatu isu atau kajian yang sedang berkembang, sebagai sarana dalam perwujudan tujuan maupun kepentingan nasionalnya. Sebuah diplomasi dilakukan dengan mempengaruhi keputusan atau pandangan pihak lain melalui dialog, negosiasi beserta cara lain yang dilakukan dengan tanpa kekerasan (www.britannica.com, diakses pada 14 November 2019). Penggunaan cara-cara tanpa adanya kekerasan, sebab hanya menekankan pada efektifitas komunikasi antara pihak-pihak yang berdiplomasi ini dapat membantu bagaimana caranya segala bentuk pandangan yang ada mampu dimoderasi dan dikomunikasikan. Dengan adanya upaya komunikasi lintas pandangan maupun persepsi yang ada, adanya proses bagaimana pihak yang terlibat memberikan pengaruh satu sama lain untuk mencapai kepentingannya. Dalam pelaksanaannya, diplomasi ekonomi menjadi sebuah salah satu bentuk diplomasi yang dilakukan oleh sebuah negara terhadap negara lain.

Diplomasi ekonomi yang dipaparkan oleh Lee \& Hocking yang memaparkan bahwa diplomasi ekonomi secara umum didefinisikan sebagai cara tradisional dalam kebutuhan diplomasi seperti agen intelijen, lobi, representatif, negosiasi dan pembelaan mengenai ekonomi politik luar negeri suatu bangsa. Menurut Lee dan Hocking "Diplomasi Ekonomi dipandang terutama sebagai hubungan antar-pemerintah, yang dilakukan oleh pejabat dinas luar negeri dan sebagai sarana untuk memajukan kepentingan ekonomi negara di negara- negara asing dan ekonomi dunia.

Tujuan dasar dari diplomasi ekonomi pada umumnya yaitu untuk memenuhi kepentingan nasional. Adapun secara khusus tujuan diplomasi ekonomi di antaranya (Donna Lee, Brian Hocking, 2010: 1216-1227): 
1. Pembuatan kebijakan luar negeri yang mendukung ekonomi untuk dapat mencapai kepentingan nasional khususnya di sektor ekonomi.

2. Mengkondisikan pemasaran dan keuangan luar negerinya sesuai dengan bagaimana kondisi global

3. Mempromosikan negara atau membangun citra negara demi menarik perhatian negara-negara lain dengan kondisi nasional.

Diplomasi ekonomi berkaitan dengan bagaimana suatu negara membuat dan mengambil keputusan dengan penggunaan instrumen ekonomi untuk mewujudkan kepentingan ekonomi melalui penyebaran pengaruh terhadap situasional maupun kebijakan ekonomi yang ada negara lain maupun organisasi internasional tertentu (Gulsara Arystankulova, 2018: 2864-2873).

Artinya bahwa diplomasi ini menekankan bagaimana atensi negara terhadap kepentingan ekonomi diprioritaskan dalam melakukan hubungan internasional dengan pihak tertentu. Selain itu, penggunaan instrumen ekonomi sebagai media pelaksanaan diplomasi ini membuatnya cukup luas untuk kemudian dikaji lebih lanjut.

Diplomasi ekonomi memiliki agenda yang komprehensif sebab berkaitan dengan perdagangan luar negeri, hubungan impor dan ekspor, kerjasama beserta perjanjian perdagangan, peluang investasi, serta komunikasi kepentingan nasional setiap negara dalam ranah ekonomi (Ibid). Mengingat bahwa tentunya setiap negara memiliki preferensi dan pertimbangan yang berbeda dalam menyusun dan menetapkan bagaimana diplomasi ekonomi ini dilaksanakan. Suatu negara akan kemudian melihat dan menyesuaikan kapabilitas yang dimilikinya untuk menggunakan peluang yang ada agar kepentingan ekonominya dapat dimaksimalkan melalui media diplomasi ekonomi untuk kesejahteraan negara yang bersangkutan, begitupun dengan Indonesia.

\section{Pasar Non Tradisional}

Kawasan yang kemudian dijadikan target sebagai pasar non tradisional merupakan wilayah yang sebelumnya belum difokuskan dan dikembangkan menjadi kawasan pengembagan ekspor bagi Indonesia, namun terlepas dari hal itu, kerjasama dengan beberapa negara di kawasan terkait sudah dibangun 
terlebih dahulu. Beberapa kawasan tertentu yang menjadi target ekspor sebagai pasar non tradisional bagi Indonesia di antaranya adalah Afrika, Amerika Latin, Asia Selatan, Asia Tengah, Timur Tengah hingga kawasan Pasifik (kemlu.go.id, diakses pada 14 November 2019).

Penetapan kawasan yang dijadikan sebagai target pasar non tradisional oleh Indonesia dipertimbangkan melalui peluang dan keuntungan yang sudah dan akan di dapat dari sektor ekspor terhadap negara-negara tertentu yang ada di kawasan tersebut. Kawasan-kawasan yang dipilih sebelumnya secara umum belum difokuskan menjadi target pasar, untuk itu dengan mempertahankan target pasar tradisional yang sudah menjadi mitra Indonesia untuk waktu yang beragam, akan menjadi kesempatan yang menjanjikan jika kemudian Indonesia mampu membuka kawasan baru dalam menginisiasi dan mengembangkan diplomasi ekonominya.

Afrika merupakan sebuah kawasan yang memiliki hubungan historis yang erat dengan Indonesia. Hal tersebut dimulai dengan dilangsungkan Konferensi Asia Afrika (KAA) tahun 1955 di kota Bandung, Indonesia yang berlangsung dari 18 April-24 April 1955 di Gedung Merdeka. KAA diikuti oleh negara-negara Asia dan Afrika yang bertujuan untuk mempromosikan kerjasama di bidang ekonomi dan kebudayaan antara negara-negara Asia dan Afrika dan juga untuk melawan kolonialisme maupun neokolonialisme dari negara- negara Amerika Serikat (AS), Rusia dan negara-negara imperialis lain. Maka, dapat dikatakan bahwa seharusnya kawasan Afrika dan negara-negara yang berada didalamnya sudah dikenal dengan baik oleh Indonesia karena hubungan dan kerjasama yang dilakukan di antara keduanya telah lama terbentuk dan keduanya memiliki hubungan historis yang luar biasa.

Bagi Indonesia, keinginan dan kebutuhan untuk mencari pasar-pasar baru atau pasar non tradisional membuat Indonesia menjadi aktif dan fokus dalam melihat Afrika sebagai pasar yang potensial bagi Indonesia dan peluang ekonomi bagi Indonesia baik untuk saat ini maupun untuk masa yang akan datang sebagaimana pendapat dari Kepala Pusat Penelitian 
Wilayah Lembaga Ilmu Pengetahuan Indonesia (LIPI), Ganewati Wuryandari (psdr.lipi.go.id, diakses pada 20 September 2020).

\section{Afika Sebagai Pasar Non Tradisional Indonesia}

Afrika pada saat ini merupakan kawasan yang berkembang dengan cepat dan merupakan kawasan yang maju. Sebelum pandemi COVID 19 melanda dunia, di mana kasus awal terjadi di Wuhan, Hubei, Cina, beberapa negara di Afrika memiliki pertumbuhan ekonomi yang sangat tinggi di atas 5\%. Diplomasi ekonomi Indonesia ke kawasan Afrika merupakan salah satu program Presiden Joko Widodo. Afrika Sub Sahara adalah kawasan yang strategis dan penting bagi Indonesia karena terdiri atas 51 negara dan jumlah populasi lebih kurang 1,1 miliar jiwa dan mempunyai potensi sumber daya alam (SDA) terutama SDA mineral yang potensial. Potensi yang dimiliki oleh negara-negara di Afrika Sub Sahara dapat dieksplor secara optimal dengan melakukan hubungan dagang dan ivestasi.

Hubungan kerjasama yang dilakukan antara negara-negara kawasan Sub Sahara Afrika dengan negara lain meningkat semakin intensif dapat dilihat dalam tataran Government to Government (G2G) berdasarkan indikator banyak negara yang membuka perwakilan dan kedutaan di kawasan Afrika. Cina dan negara-negara Eropa bergeser posisinya sebagai mitra tradisional kawasan Afrika dengan semakin banyak kerjasama dan hubungan yang terjalin antara negara-negara di kawasan Afrika dengan negara-negara lain seperti Indonesia. Hal ini dapat dilihat dari peningkatan volume perdagangan antara Indonesia dan negara-negara kawasan Afrika yaitu 1,8 kali lebih besar dari US\$ 3,8 miliar pada tahun 2010 menjadi US\$ 7 miliar pada tahun 2017, di mana produk-produk Indonesia seperti produk makanan dan minuman, obat-obatan herbal dapat dengan mudah ditemukan di Nigeria, Ghana dan negara-negara lain di kawasan Afrika, sebagaimana pernyataan Duta Besar Luar Biasa dan Berkuasa Penuh (LBBP) untuk Nigeria merangkap Ghana, Liberia, Burkina Faso, Benin, Kamerun, Togo, Republik Kongo, Niger, Sao Tome dan Principe, Gabon, Guinea Ekuator, Chad, Republik Afrika Tengah 
dan Economic Community of West African States (ECOWAS), Usra Hendra Harahap (Ibid).

\section{Strategi Diplomasi Ekonomi Indonesia ke Afrika}

Strategi pemerintah Indonesia untuk melakukan pendekatan dalam implementasi diplomasi ekonomi ke kawasan Afrika, salah satunya adalah dengan melakukan kerjasama bilateral antara Indonesia dengan negara-negara di kawasan Afrika. Salah satunya adalah negara Afrika Selatan. Indonesia fokus melakukan diplomasi ekonomi ke Afrika Selatan karena negara ini memiliki potensi yang besar tetapi belum dioptimalisasikan oleh Indonesia untuk dijadikan pasar baru atau pasar non tradisional bagi Indonesia dan untuk dijadikan sebagai negara mitra Indonesia melalui kerjasama perdagangan dan investasi di Afrika. Salah satu faktor yang membuat Indonesia melakukan diplomasi ekonomi kepada Afrika Selatan karena faktor kedekatan.

Berdasarkan catatan sejarah, interaksi pertama Indonesia dengan Afrika Selatan dapat dilihat sejak 325 tahun yang lalu dengan kedatangan Syekh Yusuf (Makasar) dan Tuan Guru Tidore. Selain itu, ada sekitar lebih kurang 1,2 juta warga Cape Malay yang merupakan keturunan Indonesia dan dianggap dapat dijadikan perekat untuk menciptakan relasi Indonesia dan Afrika Selatan yang lebih erat. Selain itu, terlaksananya KAA pada tahun 1955 dan hubungan yang baik antara para pemimpin Indonesia dengan pemimpin legendaris Afrika Selatan, yaitu Nelson Mandela hingga tercipta Batik Mandela atau yang dikenal dengan Madiba Shirt, sesuai dengan pernyataan Salman Al Farisi Duta Besar LBBP Republik Indonesia (RI) untuk Republik Afrika Selatan merangkap Botswana, Eswatini dan Lesotho yang bertempat di Pretoria (Ibid).

Selain melakukan diplomasi ekonomi melalui kerjasama bilateral, Indonesia juga melakukan penjajakan dan komunikasi dengan ECOWAS. Indonesia dan ECOWAS menyepakati persetujuan perdagangan (trade agreement) agar hambatan perdagangan, baik hambatan perdagangan tariff (pajak) dan hambatan perdagangan non-tariff (non pajak) dapat dikurangi, dari sekitar 30\% untuk hambatan tariff menjadi lebih rendah dan juga minimalisasi hambatan non pajak, sehingga ekspor dan penetrasi produk-produk Indonesia ke 
pasar Afrika dapat dilakukan dan kuantitasnya akan terus mengalami peningkatan pada tahun-tahun ke depannya. Sebagai contoh, ekspor bumbu kemasan dari Indonesia ke Afrika meningkat menjadi US\$ 61,3 juta dari total nilai ekspor Indinesia sebesar US\$ 4,76 miliar yang mengalami kenaikan sampai dengan 13,56\% per tahun dalam periode tahun 2015 sampai dengan 2019 (lipi.go.id, diakses pada 25 Oktober 2020). Komposisi ekspor produk Indonesia ke Afrika umumnya didominasi oleh produk hasil pertanian dan perkebunan, seperti minyak sawit, cengkeh, pala, kopi, rempah- rempah dan bumbu kemasan. Hal ini disebabkan karena pola konsumsi, karakteristik masakan masyarakat Afrika seperti penggunaan minyak kelapa sawit sebagai campuran makanan pokok di kawasan Afrika Barat dan budaya barbeque lokal yang sering ditemui di kawasan Afrika Timur dan Selatan, seperti pernyataan peneliti utama Pusat Penelitian Kewilayahan dan profesor di bidang sejarah lokal global, Prof. Erwiza (Ibid).

Akan tetapi, masih terdapat tantangan yang harus dihadapi oleh Indonesia dalam melakukan diplomasi ekonomi ke Afrika, yaitu masih tingginya tingkat pajak impor yang diberlakukan oleh negara-negara Afrika yang sekitar $15,15 \%$. Apabila terjadi penurunan pajak impor sebesar 1\%, maka mampu meningkatkan pertumbuhan nilai ekspor Indonesia ke kawasan Afrika sebesar 0,9\%. Hal ini berarti pemerintah Indonesia harus dapat menginisiasi kerjasama dan membuat kesepakatan perdagangan. Selain persoalan tarif, tantangan Indonesia dalam melakukan diplomasi ekonomi ke Afrika adalah karena adamya perubahan kondisi perdagangan global. Salah satunya adalah semakin banyak negara yang menerapkan proteksionisme, sehingga perlu dibentuk kerjasama antara Indonesia-Afrika dalam bentuk Free Trade Agreement dan Preferential Trade Agreement (Ibid).

Selain strategi yang telah disebutkan di atas, strategi diplomasi ekonomi yang dilaksanakan oleh Pemerintah Indonesia di kawasan Afrika, yaitu dengan melakukan diplomasi dan komunikasi kepada publik di dalam negeri. Hal ini dilakukan untuk memperbaiki mispersepsi di masyarakat Indonesia secara umum dan khususnya kepada para pemangku kepentingan (stakeholders) mengenai Afrika. Bahwa Afrika bukanlah lagi sebuah "benua hitam" atau 
kawasan yang tertinggal, tetapi Afrika pada saat ini merupakan kawasan yang mengalami kemajuan dengan pesat dan menyimpan potensi sebagai pasar non tradisional bagi Indonesia. Strategi kedua adalah melakukan pemetaan terhadap industri yang relevan dengan kawasan Afrika. Strategi ketiga adalah melakukan investasi proyek-proyek infrastruktur di Afrika melalui Lembaga Pembiayaan Ekspor Indonesia (LPEI/Indonesia Eximbank). Strategi ini telah menghasilkan berbagai kesepakatan bisnis yang bernilai jutaan dolar AS. Kesepekatan bisnis sebanyak 356 juta dolar AS yang disepakati pihak LPEI dan PT Wijaya Karya (WIKA) serta sejumlah negara-negara Afrika pada pertemuan Dialog Infrastruktur Indonesia-Afrika (IAID) di Bali pada Agustus 2019.. Strategi keempat adalah dengan menstimulus pihak swasta Indonesia untuk berinvestasi di Afrika. Pemerintah harus melakukan koordinasi dengan Kamar Dagang Indonesia (KADIN) untuk meningkatkan ketertarikan pihak swasta berinvestasi ke Afrika. Dikutip dari pernyataan Daniel Tumpal Simanjuntak, Direktur Afrika Kementerian Luar Negeri Republik Indonesia (Kemenlu RI) (www.antaranews.com, diakses pada 25 Oktober 2020).

Pemerintah Indonesia juga membentuk Satuan Tugas (Satgas) Infrastrukur yang dapat terwujud ketika penyelenggaraan Indonesia-Africa Forum (IAF) pada 2018. Satgas Infrastruktur bertugas untuk mengkoordinasikan berbagai investasi Indonesia di luar negeri, terutama di kawasan Afrika. Satgas Infrastruktur biasanya melakukan rapat koordinasi dengan berbagai kementerian dan lembaga terkait. Sebagai contoh diadakan sebuah rapat koordinasi di Cape Townyang dihadiri oleh Menteri Koordinator Bidang Kemaritiman dan Investasi (Menkomarves) RI, Duta Besar RI Pretoria dan Konsulat Jenderal RI di Cape Town dan direksi Badan Usaha Milik Negara (BUMN), seperti PT WIKA, PT TIMAH, PT Pertamina, dan Indonesia Eximbank pada Desember 2019 (Kemlu, diakses pada 26 Oktober 2020). Pemerintah mengharapkan agar penetrasi Satgas Infrastruktur ke kawasan Afrika agar dapat dilanjutkan dan juga dapat mendorong terciptanya kesepakatan-kesepakatan bisnis, sehingga dapat lebih berkembang nilainya dari kesepakan Indonesia-Africa Infrastructrure 
Dialogue (IAID) yang berlangsung pada Agustus 2019 dan menghasilakan USD 882 juta (Ibid).

Adapun berbagai kesepakatan bisnis yang dapat dicapai dalam proyek infrastruktur pada penyelenggaraan forum IAID di Bali tersebut antara lain proyek pembangunan kawasan bisnis terpadu (mixed used complex), La Tour de Goree Tower senilai US\$ 250 juta di Dakar, Senegal, selanjutnya ada proyek konstruksi rumah susun (social housing) senilai US\$ 200 juta di Pantai Gading dan proyek pembangunan bulk liquid terminal senilai US\$190 juta di Zanzibar, Tanzania.

Selain kerjasama bidang infrastruktur, ada juga pencapaian kesepakatan kerjasama di bidang farmasi senilai US\$ 1,5 juta oleh Dexa Group (Indonesia) dengan Bahari Pharmacy (Tanzania). Kemudian ada kerjasama pengembangan untuk memproduksi minyak daun cengkeh senilai US\$ 2,5 juta antara PT Indesso Aroma (Indonesia) dan Zanzibar State Trading Corporation (Zanzibar). Selanjutnya ada kesepakatan antara Kimia Farma(Indonesia) dan Topwide Pharmaceutical (Nigeria) mengenai kesepakatan distribusi sebesar US\$ 2,5 juta (Ibid). Selain menjalin kerjasama bilateral dalam implementasi strategi diplomasi ekonomi Indonesia ke Afrika dengan menekankan kepada penurunan berbagai hambatan perdagangan, Indonesia juga memiliki kerangka kerjasama multilateral dengan negara-negara di kawasan Afrika, yaitu New Asia African Strategic Partnership (NAASP). Kerangka

NAASP untuk pelaksananya adala hh Kedutaan Besar Republik Indonesia (KBRI) Pretoria di Afrika Selatan. KBRI Pretoria memiliki peran dalam tiga jalur diplomasi ekonomi yang dilakukan, yaitu Government to Government, Government to People, dan People to People (Rizky Astria Primadona, 2016).

NAASP dan IAID menjadi platform strategis bagi peningkatan kerjasama dan hubungan ekonomi Indonesia dengan Afrika di berbagai sektor, seperti infrastruktur dan manfuktur. Nilai perdagangan Indonesia dan Afrika terus meningkat seperti pada tahun 2018 mencapai lebih dari US\$ 11,6 miliar, di mana terjadi peningkatan 25\% daripada tahun 2017 (www.alinea.id, diakses pada 26 Oktober 2020). 
Selain nilai perdagangan, jumlah perusahaan Indonesia yang berinvestasi ke Afrika terus meningkat. Ada sekitar lebih kurang 30 perusahaan Indonesia berinvestasi di Afrika (sebagai contoh ada enam belas perusahaan di Nigeria dan lima perusahaan di Ethiopia) (Ibid). Implementasi kebijakan diplomasi ekonomi Indonesia harus didukung oleh berbagai perwakilan RI di luar negeri, BUMN, pihak swasta/pengusaha dan KADIN, termasuk di kawasan Afrika (https://mediaindonesia.com, diakses pada 26 Oktober 2020).

\section{KESIMPULAN}

Diplomasi ekonomi Indonesia ke Afrika dilakukan dengan empat strategi, yaitu melakukan diplomasi dan komunikasi kepada publik di dalam negeri, melakukan pemetaan terhadap industri yang relevan dengan kawasan Afrika, melakukan investasi proyek-proyek infrastruktur di Afrika melalui Lembaga Pembiayaan Ekspor Indonesia (LPEI/Indonesia Eximbank), dan menstimulus pihak swasta Indonesia untuk berinvestasi di Afrika.

Strategi diplomasi ekonomi yang dijalankan oleh Pemerintah Indonesia dilakukan dengan pendekatan Government to Government, Government to People dan People to People, di mana peran aktif perwakilan Indonesia di Afrika dan Pemerintah dengan menggandeng pihak swasta atau pengusaha termasuk juga KADIN. Pendekatan dilakukan melalui pendekatan bilateral dan multilateral seperti melalui ECOWAS. Pendekatan multilateral dan bilateral dilakukan sebagai upaya untuk mengurangi hambatan perdagangan, baik pajak maupun non pajak, sehingga pemerintah Indonesia terus mengupayakan tercapainya kesepakatan perdagangan, baik multilateral dan bilateral untuk mencapai kesepakatan FTA dan PTA. Implementasi diplomasi ekonomi ke Afrika juga dilakukan dengan strategi membentuk Satuan Tugas (Satgas) Infrastruktur sebagai lembaga yang berfungsi untuk dapat mengkoordinasikan investasi Indonesia di luar negeri dan terutama di Afrika.

Diplomasi ekonomi Indonesia ke Afrika dilakukan melalui platform strategis, dua diantaranya melalui NAASP dan IAID. NAASP dan IAID menjadi 
strategi Indonesia untuk semakin meningkatkan dan mengintensifkan hubungan dan kerjasama Indonesia dengan negara-negara Afrika, pada khususnya peningkatan kerjasama di bidang ekonomi.

\section{DAFTAR PUSTAKA}

AntaraNews.com, Empat Strategi Diplomasi Ekonomi Indonesia di Afrika, (internet) 28 Oktober 201, 25 Oktober 2020, https://www.antaranews.com/berita/1135611/empat-strategi-diplomasi$\underline{\text { ekonomi- indonesia-di-afrika }}$

Badan Pengkajian dan Pengembangan Kebijakan Perdagangan, Kementrian Perdagangan RI, "Peluang Ekspor Indonesia di Pasar Negara-Negara Non-Tradisional". $\quad$ Internet, 25 Januari 2020,http://bppp.kemendag.go.id/media_content/2017/08/Peluang_Ekspor _Indonesia_di_Pasar_Negara-Negara_Non_Tradisional.pdf

Barston, Ronald Peter. 2006. Modern diplomacy. Pearson Education.

Budi Winarno. 2017. “Globalisasi dan Krisis Demokrasi” Yogyakarta: MedPress.

Center for Area Studies Indonesian Institute of Sciences (P2W-LIPI), Diplomasi Ekonomi Indonesia dan Afrika, (internet) 20 September 2020, 25 Oktober 2020, http://psdr.lipi.go.id/news-andevents/news/diplomasi-ekonomi-indonesia-dan- afrika.html

Creswell , Jhon W. 2016. Pendekatan Metode Kualitatif, Kuantitatif, dan Campuran, Edisi Keempat, Terj. Achmad Fawaid dan Rianayati Kusmini Pancasari, Yogyakarta: Pustaka Pelajar.

Creswell, John W. 2010. Research Design: Pendekatan Kualitatif, Kuantitatif dan Campuran, Yogyakarta : Pustaka Pelajar.

Eko Sulistyo, "Forum Indonesia-Afrika 2018”. Internet, diakses pada 10 Februari 2020,http://ksp.go.id/forum-indonesia-afrika-2018/

Encyclopedia Britannica, "Diplomacy | Nature, Purpose, History, \& Practice", internet 14 November 2019, https://www.britannica.com/topic/diplomacy

Gulsara Arystankulova. 2018. "Economic Diplomacy - Important Component Of Foreign Policy Of Modern State”, The Turkish Online Journal of Design, Art and Communication Special Edition.

Haufan Hasyim Salengke, Indonesia Pacu Diplomasi Ekonomi ke Kawasn Afrika dan Timteng , (internet), 8 Januari 2020, 26 
Oktober 2020, https://mediaindonesia.com/read/detail/281975indonesia-pacu-diplomasi-ekonomi- ke-kawasan-afrika-dan-timteng

Kementerian Luar Negeri Republik Indonesia, "Menteri Luar Negeri Ri Retno L. P. Marsudi

Penyampaian Prioritas Politik Luar Negeri Republik Indonesia 20192024",https://kemlu.go.id/portal/id/read/725/pidato/penyampaian-prioritaspolitik-luar- negeri-republik-indonesia-2019-2024 diakses pada 14 November 2019

Kementerian Luar Negeri Republik Indonesia, Satgas Infrastruktur Indonesia Pertajam

Diplomasi Ekonomi di Kawasan Afrika, (internet) 21 Desember 2019, 26 Oktober 2020, https://kemlu.go.id/portal/id/read/916/berita/satgasinfrastruktur-indonesia- pertajam-diplomasi-ekonomi-di-kawasan-afrika

Kementrian Perdagangan RI, "Neraca Perdagangan Indonesia dengan Rep. Afrika Selatan”. Internet, 1 Februari 2020, https://www.kemendag.go.id/id/economic- profile/indonesia-exportimport/balance-of-trade-with-trade-partner- country?negara $=261$

Lee, Donna and Brian Hocking. “'Economic Diplomacy' in Robert A”. (Denmark: The International Studies Encyclopedia, 2010.) Vol. II. Wiley Blackwell.

Lembaga Ilmu Pengetahuan Indonesia (LIPI), Menguatkan Diplomasi Ekonomi Indonesia- Afrika melalui Budaya Makanan, (internet) 23 Oktober 2020, diakses 25 Oktober 2020, http://lipi.go.id/siaranpress/Menguatkan-Diplomasi-Ekonomi-IndonesiaAfrika-Melalui-Budaya-Makanan/22196

Lexy J Moleong. 2007. Metodologi Penelitian Kualitatif, Bandung: PT. Remaja Rosdakarya Bandung.

Mansour Fakih. 2004. "Neoliberalisme dan Globalisasi", Ekonomi Politik Digital Journal Al-Manar, Edisi I

Rizky Astria Primadona, Diplomasi Ekonomi Indonesia di Sub Sahara: Penguatan Hubungan

Kerjasama Ekonomi antara Indonesia dan Afrika Selatan dalam Kerangka NAASP (2010-2014), tesis, Departemen Ilmu Hubungan Internasional Fakultas Ilmu Sosial dan Ilmu Politik Universitas Gadjah Mada, Yogyakarta, 2016. 
Septiawan Santana K, Menulis Ilmiah Metodologi Penelitian Kualititatif, Jakarta: Yayasan Pustaka Obor Indonesia, 2010.

Steans, J. and Pettiford L. 2005. "Introduction to International Relations: Perspective and Themes.” New Jersey: Pearson Prentince Hall.

Sugiyono. 2011. Metode Penelitian Kuantitatif dan Kualitatif dan R\&D, Bandung: Alfabeta.

Sulthon Sjahril Sabaruddin, "Penguatan Diplomasi Ekonomi Indonesia Mendesain Clustering Tujuan Pasar Ekspor Indonesia: Pasar Tradisional vs Pasar Non-Tradisional”. Universidad de Colime, Mexico.

Valerie Dante (Pradita University), IAID 2019 Wujud Diplomasi Ekonomi Indonesia, (internet) 21 Agustus 2019, 26 Oktober 2020, https://www.alinea.id/dunia/iaid-2019-wujud-diplomasi-ekonomiindonesia-b1Xle9mAP. 